\title{
Sources of Inspiration: A Neurophysiologic Framework for Understanding Anesthetic Effects on Ventilatory Control
}

\author{
Maureen E. Czick • Jeffrey C. Waldman • \\ Jeffrey B. Gross
}

Published online: 7 December 2013

(C) Springer Science + Business Media New York 2013

\begin{abstract}
Almost every medication that is presently available to provide sedation, analgesia, or general anesthesia significantly depresses one or more ventilatory control mechanisms. This places patients at risk of developing hypoventilation and hypoxemia during moderate or deep sedation as well as general anesthesia. As the neurophysiologic processes underlying normal ventilatory drive are discovered, new insights into the influence of anesthetics on ventilation have been recognized. More importantly, research into ways to circumvent these effects is underway. For example, drugs such as serotonin agonists and ampakines have been shown to counteract opioidinduced ventilatory depression without reversing the analgesic effect. On the other hand, efforts to identify agents that reverse the respiratory depression associated with propofol and the inhalation anesthetics have been less promising. Until reliable means for reversing drug-induced ventilatory depression are developed, prompt recognition of ventilatory insufficiency and initiation of resuscitative measures remain the keys to patient safety.
\end{abstract}

Keywords Anesthesia - Anesthetics · Ventilation . Breathing · Opioids · Propofol

M. E. Czick · J. C. Waldman · J. B. Gross ( $)$

Department of Anesthesiology, University of Connecticut

School of Medicine, Farmington, CT 06030-2015, USA

e-mail: gross@neuron.uchc.edu

M. E. Czick

e-mail: meczick@yahoo.com

J. C. Waldman

e-mail: jwaldman@ resident.uchc.edu

M. E. Czick

Hartford Hospital, Hartford, CT 06102, USA

\section{Introduction}

An article published a decade ago summarizes a problem that anesthesiologists confront every day of their professional lives: "When you breathe in you inspire. When you don't breathe, you...expire" [1]. Medical advances arrive at an ever-increasing pace, but the fact that inadequate oxygenation leads to death remains an unavoidable constant of human biology.

Most of the drugs used by anesthesiologists to provide sedation, analgesia, and general anesthesia have well-recognized depressant effects on ventilatory drive. In the operating room, under the watchful eyes of an anesthesiologist, ventilatory depression or cessation can be readily identified and safely managed with positive pressure ventilation, with or without insertion of airway devices. However, this is not always the case [2]. In the American Society of Anesthesiologists' Closed Claims Study, $6 \%$ of claims were due to injuries occurring during attempted airway management after induction of anesthesia; $8 \%$ of these injuries resulted in death [3]. Increasing obesity rates in the decades since the Closed Claims Study have only augmented the risks. A 2012 study from the UK revealed that, among pregnant women undergoing cesarean section, there was a $7 \%$ increase in the incidence of failed intubation for each $1 \mathrm{~kg} \mathrm{~m}^{-2}$ increase in BMI above normal [4].

The risk of ventilatory depression extends into the postoperative period. Patients who have just emerged from general anesthesia, with varying combinations of inhaled anesthetics, benzodiazepines, and opioids, remain at risk in the post-anesthesia care unit, where recognition of inadequate ventilation may be delayed. Ambulatory patients are discharged from the post-anesthesia care unit to their homes, often having received an additional dose of opioid to make the trip more comfortable. 
Anesthesiologists grapple constantly with the question, "If my patient receives drug X, could dangerous levels of hypoxemia occur?" Unfortunately there is rarely an easy answer. To safely navigate the dangerous waters of impaired ventilation, it is natural to consult the clinical and scientific literature for guidance. However, the neurologic regulation of ventilation is complex and dependent upon many variables: Some are as obvious as the neurological differences between neonates and adults, while others are as unexpected as sex hormone-mediated differences in the response to chronic hypoxia, and several are still subject to ongoing scientific debate.

The ventilatory effects of sedative and analgesic agents were reviewed by Cerza and Gross in 2003 [5]. A 10 -year mark often provides impetus to reassess progress in the field and to consider potential avenues for ongoing research. The present review outlines important recent observations about the effects of anesthetics on ventilation, building upon earlier results and considering areas where further studies are needed. We limit our focus to the three principal drug classes that are mainstays of current anesthesia practice: propofol, opioids, and inhalational anesthetics.

In contrast to previous reviews, we utilize a two-pronged approach to create a conceptual framework that makes interpreting the pharmacological results more manageable. We first provide a brief overview of the neurophysiologic components of the ventilatory control process. We then describe how each of the drugs interacts with one or more components of this control system to depress ventilatory drive. Breaking down a complex, integrated process into separate components is likely to introduce some degree of oversimplification. But it is our hope that this approach will improve insight into this critically important aspect of our practice.

\section{Overview of Inspiratory Neuroregulation}

The mechanics of inhalation are fairly simple; the diaphragm and external intercostal muscles contract, altering the geometry of the thoracic cavity, and thereby increase its volume. By Boyle's law, this increased volume decreases the pressure within the thorax, establishing a pressure gradient between the outside air and the alveoli, causing air to flow into the lungs. However, the neural steps that culminate in the contraction of the inspiratory muscles are anything but simple.

Spontaneous breathing is an unconscious activity, originating from the innate electrical excitability of patterngenerating neurons within the brainstem. Its rate and magnitude are influenced by an enormous number of modulating inputs from reflexes that assess lung volume and wakefulness, as well as blood gas tensions and acid- base balance. At the same time, breathing is a conscious activity, with its unconscious control mechanisms subject to temporary overrides by higher brain centers during speech, singing, voluntary hyperventilation or breath holding. Because of this complexity, it is helpful to examine the roles of the principal neural components individually, focusing on those most relevant to anesthetic effects on ventilation.

\section{The Inspiratory Pattern Generator}

Just as the heart has a pacemaker of sinoatrial cells that rhythmically depolarize, signaling the cardiac chambers to contract [6-9], the medulla contains specialized respiratory pacemaker cells, whose action potentials periodically trigger contraction of the muscles of inspiration, generating the respiratory rhythm. The neurons of the PreBotzinger Complex in the ventrolateral medulla are now generally regarded as the initiation site for the electrical activity that culminates in normal inspiration $[10,11]$. However, this conclusion was only reached after two decades of experimentation and debate [12-14].

In the late 1980s and early 1990s, researchers identified two potential candidate generators for respiratory rhythm, both located in the medulla: the PreBotzinger Complex (preBOTc) and the Retrotrapezoid Nucleus/ParaFacial Respiratory Group (RTN/pFRG) [15-18]. Neurons from both areas spontaneously exhibit non-triggered bursts of electrical activity in isolated tissue sections taken from the brainstems of experimental animals. In "en bloc" preparations (in which the brainstem through the thorax is harvested from the animal with neurologic connections remaining intact), the innate electrical activity of preBOTc and RTN/pFRG neurons closely precedes depolarization of the phrenic nerves, suggesting that either of these sites might be the true ventilatory pacemaker. In keeping with these observations, the preBOTc was often referred to in the literature as the putative pacemaker, while the RTN/ pFRG neurons were designated "pre-inspiratory" (pre-I) neurons [19]. However, as Guyenet and Mulkey [19] observe, the pre-I nomenclature fails to account for the fact that RTN/pFRG neurons generate action potentials both before and after depolarization of the phrenic nerve; in fact, the majority of RTN/pFRG activity occurs after the phrenic nerve discharges.

Over time, evidence gradually mounted that the preBOTc is the true source of inspiratory drive. In animal models, lesions of the preBOTc cause permanent impairment of the inspiratory pattern $[13,18]$. Knockout mice lacking the transcription factor mafB (and therefore having a significantly reduced number of preBOTc neurons) exhibit severely abnormal breathing patterns and die at birth. Neurons harvested from these mafB -/- mice demonstrate defective in vitro 
respiratory rhythmogenesis $[13,20]$. The discrepancy in experimental findings can be explained by the fact that the original experiments implicating the RTN/pFRG as a respiratory rhythm generator were performed in neonatal rather than adult rodents, and the animals' age was critical for the findings [15-17]. Subsequent studies revealed that the RTN/ pFRG does indeed generate inspiratory rhythm, but only in the very early neonatal period; it cedes that role to the preBOTc shortly thereafter [13].

An interesting and credible theory to explain the dual neonatal sites for inspiratory drive comes from the fact that the preBOTc expresses opioid receptors, while the RTN/ pFRG does not. At birth, mammals experience a massive release of endogenous opioids to help with the immense stress of the birth process. If the opioid-vulnerable preBOTc neurons were the only functioning inspiratory generator at the time of this opioid surge, it would likely lead to fatal apnea. So the RTN/pFRG serves as an alternative rhythm generator in the neonatal period. In support of this hypothesis, knockout mice lacking the Krox 20 gene (and therefore lacking RTN/pFRG neurons) die from apnea on day one of life unless naloxone is administered to shield the preBOTc from the endogenous opioid burst [13, 21]. With naloxone to safeguard them through this critical period, these mice live normally, even without the RTN/pFRG. This provides further evidence that the preBOTc and not the RTN/pFRG serves as the primary pacemaker for inspiration after the neonatal period.

\section{Central Chemoreceptors}

The preBOTc does not function in isolation. Just as sinoatrial cells receive modulating inputs from the autonomic nervous system to alter the heart rate, the preBOTc receives input from central chemoreceptors to increase ventilation in response to the decrease in $\mathrm{pH}$ that is associated with elevated partial pressures of $\mathrm{CO}_{2}$ in the brain $[11,22]$. Although not all central chemoreceptors are found in the brainstem, many of those that are relevant to the discussion of anesthetic effects upon ventilation are located there [23]. The RTN/pFRG appears to be a very important central chemoreceptor [19], as are the serotonergic neurons of the raphe in the medulla [24] and the locus ceruleus in the pons [25]. Doi et al. [22] cleverly modeled the many inputs to the respiratory rhythm generator as a "see-saw" with inhibitory inputs on one side and facilitating inputs on the other, all working in tandem to modulate the pattern generator's activity slightly upward or downward.

\section{Peripheral Chemoreceptors}

The peripheral chemoreceptors in the carotid bodies are the primary mediators of the hypoxic ventilatory response
(HVR); they signal the preBOTc to increase ventilatory output in the presence of hypoxia, acidosis, and to a lesser extent elevations in arterial $\mathrm{PCO}_{2}$. The carotid bodies are neural-crest-derived structures located at the carotid bifurcations, deriving their substantial blood supply (the highest blood flow per unit of mass of any organ in the body) from the external carotid arteries [26]. The carotid body glomus cells respond to the $\mathrm{P}_{\mathrm{a}} \mathrm{O}_{2}$ rather than the oxygen saturation. When the $\mathrm{P}_{\mathrm{a}} \mathrm{O}_{2}$ falls below approximately $60 \mathrm{mmHg}$, glomus cell $\mathrm{K}^{+}$background leak channels close and outward $\mathrm{K}^{+}$flux ceases, causing the glomus cells to depolarize. This opens voltage-sensitive $\mathrm{Ca}^{2+}$ channels, permitting $\mathrm{Ca}^{2+}$ influx. The glomus cells then behave as presynaptic neurons, releasing neurotransmitter vesicles to trigger action potentials in nearby afferent terminals from the carotid sinus branch of cranial nerve IX. The action potentials travel via this nerve to the nucleus of the tractus solitarius, the major sensory input terminal of the medulla, where they depolarize interneurons, which synapse with the preBOTc [26]. The primary effect of hypoxemia is to increase the gain of the ventilatory response to $\mathrm{CO}_{2}$ rather than to serve as a primary ventilatory control mechanism [27].

The mechanism by which glomus cells detect oxygen levels remains unclear [28]. One theory is that glomus cell mitochondria are the oxygen sensors, since the ATP production apparatus is the final destination of diffusible oxygen. However, mitochondrial uncouplers, which inhibit the electron transport chain, fail to block the glomus cell response to hypoxia [26]. Another theory is that the oxygen sensor is glomus cell NADPH oxidase, which turns molecular oxygen into superoxide anion. However, knockout mice lacking the gp91phox component of NADPH oxidase exhibit a normal HVR [29, 30]. Finally, it has been suggested that glomus cell $\mathrm{K}^{+}$channels may be directly oxygen-sensitive, requiring adequate oxygen levels to remain open. This is a credible theory since oxygensensitive $\mathrm{K}^{+}$channels from the TASK family have been characterized [31]. Thus far, TASK 3 knockout mice have not shown impaired HVR [32, 33], while TASK 1 knockout mice have shown either diminished or unchanged HVR [32, 33]. Thus, the mechanism of $\mathrm{PO}_{2}$ sensing by the glomus cells remains an important area for future investigation.

\section{Inspiratory Premotor Neurons}

Once the action potential for inspiration has been generated, it must be transmitted to the spinal cord motor neurons that power the diaphragm and external intercostal muscles [34, 35]. The conduits between the preBOTc and the spinal cord are the bulbospinal inspiratory neurons of the ventral respiratory group (VRG) and the dorsal respiratory group (DRG). These VRG and DRG neurons are 
called "premotor neurons," since they synapse with the inspiratory motor neurons: the phrenic nerves in the cervical spinal cord and the nerves to the external intercostal muscles in the thoracic spinal cord.

\section{Anesthetic Effects upon the Pattern Generator}

Inhalational Anesthetics

Inhalational anesthetic agents have well-recognized depressant effects upon ventilation, but the mechanism by which this occurs (as well as the mechanism by which they produce general anesthesia) has proven elusive. These clinical effects might result from a direct effect upon the pattern generator; alternatively, they could reflect decreased chemoreceptive inputs to the pattern generator (see below). It is important to note that, unlike propofol, volatile anesthetic agents do not themselves result in apnea, an effect likely due to activation of RTN neurons [36].

\section{Opioids}

Experiments in knockout mice lacking exon two of the muopioid receptor gene confirm that this receptor is the molecular mediator of both morphine-induced analgesia $[37,38]$ and morphine-associated respiratory depression [39]. The inhibitory effects of mu receptor agonists upon the preBOTc have been well described [40]. Opioid drugs cause a "quantal" respiratory pattern [41], in which the output of the preBOTc remains regular, but not all preBOTc action potential bursts are successfully conducted through the respiratory network to trigger inhalation-a pattern likened to Mobitz II second-degree AV block [40].

Until recently, opioid analgesia and respiratory depression seemed inextricably linked because of the mu receptors expressed on preBOTc neurons. Yet alternative methods to preserve ventilatory drive without compromising analgesia may be possible. One longstanding approach aimed to exploit the pharmacologic distinction between splice variants of the mu opioid receptor gene. According to pharmacologic models, $\mathrm{mu}_{1}$ receptors are considered to primarily mediate analgesia, while $\mathrm{mu}_{2}$ receptors are believed to be responsible for ventilatory depression. Unfortunately, this splice variant functional distinction remains unproven clinically, and attempts to develop compounds with preferential affinity for $\mathrm{mu}_{1}$ receptors have not yet proven fruitful. Morphine-6-glucuronide (M6G) has four- to fivefold less affinity for $\mathrm{mu}_{2}$ receptors than morphine itself, suggesting that M6G would be less likely to depress ventilation. While initial studies were promising, subsequent investigations showed that when equi-analgesic doses of M6G and morphine were compared, the ventilatory depressant effects were similar after all [42].

More recent investigations have examined the potential use of serotonin to counteract opioid-induced ventilatory depression because of its physiologic role in stimulating preBOTc neurons to augment ventilation in the presence of increased $\mathrm{PCO}_{2}$ [43]. In contrast to opioid antagonists, which reverse both ventilatory depression and analgesia, serotonin agonists are unlikely to affect analgesia since mu-expressing pain neurons do not express serotonin receptors [40]. Buspirone, which acts at the 5-hydroxytryptamine $1_{\mathrm{A}}$ receptor $\left(5-\mathrm{HT} 1_{\mathrm{A}}\right)$, was the first serotonin agonist found to stimulate ventilation in an animal model [44]. More than a decade later, Sahibzada et al. [45] found that buspirone as well as another 5-HT1 $1_{\mathrm{A}}$ receptor agonist, 8-hydroxy-2-(di-n-propylamino)tetralin (8-OH-DPAT), reverses morphine-induced apnea in both spontaneously breathing and mechanically ventilated, anesthetized rats. In brainstem slices, Wang et al. [46] found that both 8-OH-DPAT and BIMU-8, an agonist of the 5-HT4 $\alpha$ receptor, prevent fentanyl-induced respiratory depression. Recently, Guenther et al. [47] showed that 8-OH-DPAT and another $5-\mathrm{HT} 1_{\mathrm{A}}$ receptor agonist, repinotan, stimulate ventilation in a dose-dependent fashion in brainstem-spinal cord preparations as well as in anesthetized rats [48, 49••]. In anesthetized mice, BIMU-8 blocks the apneic effects of fentanyl, without reversing its pain-suppressing effect [50].

Unfortunately, the promise of 5-HT1 and 5-HT4 agonists to reverse opioid-induced ventilatory depression has not yet been realized in the clinical realm. Few such medications are currently approved for human use, and results have been disappointing. In human volunteers, neither buspirone [51] nor mosapride, a 5-HT4 agonist [52], had any impact on morphine-induced ventilatory depression. Repinotan's potential to reverse opioid ventilatory depression has not yet been investigated.

Another possibility for counteracting opioid-induced ventilatory depression involves $\alpha$-amino-3-hydroxy-5methyl-4-isoxazolepropionic acid (AMPA) glutamate receptors, which modulate respiratory rhythm: Blockade of these receptors decreases the respiratory rate, whereas their stimulation increases respiration [53]. Two different modulators of AMPA receptors, called ampakines [54], have been shown to attenuate opioid-induced respiratory depression in animal models, without affecting opioid-induced analgesia. Ren et al. [55] found that the ampakine CX546 counteracts the opioid-induced depression of ventilatory drive in both brainstem slices and en-bloc preparations. Similar results were observed in newborn rats, again with no reduction in opioid-induced analgesia. A follow-up investigation in rats showed that preadministration of the ampakine CX717 significantly attenuates fentanyl-induced respiratory depression [56] and rescues animals from lethal doses of fentanyl without affecting fentanyl's analgesic effect. 
Oertel et al. [57••] published the only human study to examine the influence of ampakines on opioid-induced analgesia and ventilatory depression. Sixteen healthy volunteers were treated with either placebo or a single oral dose of ampakine CX717 during alfentanil infusion. In contrast to placebo, CX717 partially reversed the alfentanil-induced decrease in respiratory rate, minute ventilation, and slope of the $\mathrm{CO}_{2}$ response curve. Importantly, CX717 did not affect pain tolerance, suggesting ampakines may be a clinically useful reversal agent for opioid-induced respiratory depression.

\section{Propofol}

The use of ampakines to mitigate propofol-induced respiratory depression has recently been proposed. Ren et al. [58••] showed the pre- or co-administration of CX717 with propofol diminished subsequent ventilatory depression in several rodent preparations. However, when propofol was administered first, CX717 was not effective in reversing ventilatory depression. Certainly, further research on the use of ampakines is warranted.

\section{Anesthetic Effects upon the Central Chemoreceptor- Mediated Hypercapnic Ventilatory Response (HCVR)}

\section{Propofol}

The respiratory depressant effects of propofol were well established soon after propofol was introduced. Two separate groups demonstrated that the decreased minute ventilation observed after a propofol bolus is more attributable to decreased tidal volume than to decreased respiratory rate [59, 60]. After induction of anesthesia with propofol (2.0-2.5 mg kg $\mathrm{mg}^{-1}$ ) alone, periods of apnea more than $30 \mathrm{~s}$ occur in at least $60 \%$ of patients [61-64]. These episodes may extend to $60 \mathrm{~s}$ or more in 33-50\% of patients receiving the same dose of propofol after pretreatment with an opioid $[59,65,66]$. Shortly thereafter, propofol's depressant effects were linked to both central and peripheral chemoreceptors.

Goodman et al. found that the HCVR decreases to $58 \%$ of its baseline after a $2.5 \mathrm{mg} \mathrm{kg}^{-1}$ bolus of propofol followed by an infusion of $100 \mathrm{mcg} \mathrm{kg}^{-1} \mathrm{~min}^{-1}$ [64]. Blouin et al. [67] demonstrated that the slope of the $\mathrm{CO}_{2}$ response curve decreases by $56 \%$ after a $2.5 \mathrm{mg} \mathrm{kg}^{-1}$ bolus of propofol. Importantly, the slope remains depressed up to $20 \mathrm{~min}$ after the propofol bolus, despite patients being fully awake at that time, suggesting that the ventilatory effects of propofol may outlast its sedative properties. A later study used a dynamic end-tidal forcing technique to determine whether propofol-induced ventilatory depression results from effects on the peripheral or the central chemoreflex loop. At plasma concentrations of 0.5 and $1.3 \mathrm{mcg} \mathrm{ml}^{-1}$, central $\mathrm{CO}_{2}$ sensitivity was reduced by 20 and $34 \%$ respectively, while there was no effect on the peripheral chemoreflex loop [68].

The mechanism by which propofol depresses HCVR has not been determined, but a potential clue comes from studies of propofol's vasodilating effects. In vascular smooth muscle, propofol inhibits the L-type calcium channel [69-72]. Since the chemosensory responsiveness of locus ceruleus neurons depends on these channels [25, 73], propofol-induced depression of HCVR may be related to an inhibitory effect upon L-type calcium channels in central chemoreceptor neurons.

Inhalation Anesthetics

In 1966, Munson et al. [74] published one of the earliest studies in humans to demonstrate the dose-related depression of the ventilatory response to carbon dioxide by halothane, fluroxene, and cyclopropane. Modern inhalation anesthetics, isoflurane [75, 76], sevoflurane [77], and desflurane [78], have similar effects. At 1.1-1.2 minimum alveolar concentration (MAC), these agents decrease the tidal volume by 50-70\%, while they increase the respiratory rate by $43-56 \%$. Overall, minute ventilation decreases by $12-28 \%$, causing $\mathrm{PaCO}_{2}$ to rise by as much as $32 \%$.

The results of studies on HCVR in the presence of subanesthetic concentrations of inhaled agents have been variable. Some investigators showed no difference in HCVR between unanesthetized controls and test subjects at 0.1 MAC isoflurane [79, 80] or sevoflurane [81]. Others showed decreased $\mathrm{CO}_{2}$ sensitivity, 24-45\% below resting values $[82,83]$. Interestingly, a subanesthetic concentration of desflurane does not appear to influence HCVR. [83].

\section{Opioids}

The effects of opioids on HCVR are well established. At low doses $\left(<0.5 \mathrm{mg} \mathrm{kg}^{-1}\right)$, morphine shifts the $\mathrm{V}_{\mathrm{E}}$ versus $\mathrm{PCO}_{2}$ response curve to the right without changing its slope. At higher concentrations, the slope of the curve tends to decrease, possibly related to changes in the level of consciousness [84].

\section{Anesthetic Effects upon the Peripheral Chemoreceptor- Mediated Hypoxic Ventilatory Response (HVR)}

\section{Propofol}

Propofol significantly depresses HVR in a dose-dependent manner. Separate studies demonstrated 61 and $80 \%$ decreases in HVR at plasma concentrations of 2.1 and 
$2.2 \mathrm{mcg} \mathrm{ml}^{-1}$, respectively $[85,86]$. Nieuwenhuijs et al. [87] used acute steps into and out of hypoxemia to subdivide the HVR into an acute hypoxic response (AHR) mediated by the peripheral chemoreceptors and a delayed hypoxic ventilatory decline (HVD), which is mediated centrally. They found that a low-dose propofol infusion (mean plasma concentration $0.6 \mathrm{mcg} \mathrm{ml}^{-1}$ ) decreases the AHR by $50 \%$, reflecting an influence on peripheral chemoreceptors; propofol also increases the ratio of $\mathrm{HVD} /$ AHR, suggesting an effect on the centrally mediated responses.

Just as with HCVR, the mechanism by which propofol inhibits HVR in unknown. However, the dependence of glomus cell neurotransmitter-release upon voltage-gated $\mathrm{Ca}^{2+}$ channels may offer a plausible explanation, given propofol's well-documented effects on the L-type calcium channel [69-72]. Propofol has also been shown to affect certain $\mathrm{K}^{+}$channels in arterial smooth muscle [88]. Therefore, future research could address the glomus cell $\mathrm{K}^{+}$ channel as the site of propofol's inhibition of HVR. Alternatively, propofol is a documented uncoupler of complex I of the mitochondrial electron transport chain [89]; in view of the postulated role of mitochondria in HVR, propofol's inhibitory effect could be mediated at that site.

\section{Inhalational Anesthetics}

The effect of inhaled anesthetics on HVR are controversial, and conflicting results appear in the literature. Early experiments by Knill et al. [76] showed that, with carbon dioxide levels held constant (isocapnia), isoflurane depresses the HVR by nearly $60 \%$ at 0.1 MAC and abolishes it at 1.1 MAC. An important confounding factor in assessing the effect of subanesthetic concentrations of inhaled agents on HVR appears to be the degree of sensory stimulation, and thus the depth of unconsciousness, of the research subjects during exposure to the anesthetics [90, 91]. Van den Elsen et al. [82] demonstrated that, in the absence of audiovisual stimulation, 0.1 MAC isoflurane decreases isocapnic HVR by $48 \%$; in the presence of such stimulation, the corresponding decrease is only $11 \%$ [83].

In other studies where end-tidal $\mathrm{CO}_{2}$ was not artificially clamped to a constant value (poikilocapnia), 0.85 MAC isoflurane did not significantly depress HVR probably because of the interaction between the central and peripheral ventilatory control mechanisms $[92,93]$. HCVR is much larger than HVR under most conditions, and so when $\mathrm{CO}_{2}$ is allowed to rise, the stimulation of ventilation by HCVR may simply render anesthetic depressant effects upon HVR inconsequential. Desflurane appears to act differently than other anesthetics: 0.1 MAC desflurane does not depress HVR during isocapnia, perhaps because of its propensity to cause airway irritation [94].
Hypotheses regarding the mechanism by which HVR is inhibited by these drugs remain speculative. However, important clues have emerged. Subanesthetic concentrations of volatile anesthetics increase the probability that TASK- $1 \mathrm{~K}^{+}$channels are open $[31,95] . \mathrm{O}_{2}$-sensitive $\mathrm{K}^{+}$ channels contribute to one possible mechanism for initiating the carotid body glomus cell HVR signaling (see above). Inhibition of HVR by isoflurane may be reversed by the administration of antioxidants [96], suggesting a role for reactive oxygen species (ROS) generated by volatile anesthetic agents in mediating their inhibition of HVR. Desflurane may differ from other volatile anesthetics with regard to generation of ROS, but results have been variable. In a study of mitochondrial function in apoptosis, isoflurane led to increased ROS levels and opening of the mitochondrial permeability transition pore, while desflurane did not [97]. However, it has been suggested that desflurane-mediated cardioprotective ischemic postconditioning occurs through generation of ROS [98, 99]. Further study is needed to clarify the role of desflurane in ROS production and its potential implications for ventilatory control.

\section{Anesthetic Effects upon Inspiratory Premotor Neurons}

\section{Inhalational Agents}

Excitatory input from chemoreceptors to inspiratory and expiratory premotor neurons is mediated by N-methyl-Daspartic acid (NMDA) neurotransmission at glutamate receptors [34, 35, 100-102]. Further modulation comes from gamma-aminobutyric $\operatorname{acid}_{\mathrm{A}}\left(\mathrm{GABA}_{\mathrm{A}}\right)$ inhibitory input [103]. Inspiratory neurons also demonstrate reciprocal self-excitation during the inspiratory phase, which is mediated by alpha-amino-3-hydroxy-5-methylisoxazole-4propionate receptors $[34,104]$.

Stuth et al. [105] developed a decerebrate, vagotomized, and peripherally deafferented canine model to measure changes in brainstem respiratory neurons in response to inhalational anesthetics. In a series of experiments, they demonstrated that halothane reduces glutamatergic excitation by $32 \%$ while enhancing $\mathrm{GABA}_{\mathrm{A}}$ ergic inhibition by $12 \%$ [106]. Similarly, sevoflurane depresses glutamatergic excitation and enhances $\mathrm{GABA}_{\mathrm{A}}$ ergic inhibition by 20 and $19 \%$, respectively [107]. Postsynaptic NMDA receptor responsiveness was unaffected in these experiments; the effects resulted from presynaptic reduction of glutamatergic excitatory neurotransmission. Unfortunately, the experimental protocol did not enable determination of the site of enhanced $\mathrm{GABA}_{\mathrm{A}}$ ergic activity. In a subsequent study, these authors found that postsynaptic $\mathrm{GABA}_{\mathrm{A}}$ ergic receptor activation (which results in ventilatory depression) increases by 
$65 \%$ during 1 MAC sevoflurane and $75 \%$ during 1 MAC halothane exposure [108]. Since this exceeds the overall inhibitory effect of the volatile agents, the authors concluded that inhalation anesthetics actually decrease presynaptic $\mathrm{GABA}_{\mathrm{A}}$ inhibition of ventilatory drive.

\section{Conclusion}

While the ventilatory depression associated with sedative, analgesic, and anesthetic agents has been known for decades, it is only recently that we have begun to understand the molecular mechanisms underlying these effects. Over the past 2 decades, the tools of the molecular biology revolution have led to strategies that might effectively counteract the undesirable ventilatory effects of these drugs while maintaining their efficacy. Until methods become available to provide sedation, analgesia, and anesthesia without subjecting patients to life-threatening ventilatory depression, only the vigilance of the anesthesiologist keeps patients inspiring so they won't...expire [1].

\section{Compliance with Ethics Guidelines}

Conflict of Interest Maureen E. Czick, Jeffrey C. Waldman, and Jeffrey B. Gross declare that they have no conflict of interest.

Human and Animal Rights and Informed Consent This article does not contain any studies with human or animal subjects performed by any of the authors.

\section{References}

Papers of particular interest, published recently, have been highlighted as:

•• Of major importance

1. Gross JB. When you breathe IN you inspire, when you DON'T breathe, you...expire: new insights regarding opioid-induced ventilatory depression. Anesthesiology. 2003;99:767-70.

2. Kheterpal S, Healy D, Aziz MF et al. Incidence, predictors, and outcome of difficult mask ventilation combined with difficult laryngoscopy: a report from the multicenter perioperative outcomes group. Anesthesiology. 2013;119:00-00. doi:10.1097/ ALN.0000435832.39353.20.

3. Domino KB, Posner KL, Caplan RA, et al. Airway injury during anesthesia. Anesthesiology. 1999;91:1703-11.

4. Quinn AC, Milne D, Columb M, et al. Failed tracheal intubation in obstetric anaesthesia: 2 year national case-control study in the UK. Br J Anaesth. 2013;110:74-80.

5. Cerza DA, Gross JB. Pharmacology and pathophysiology of the control of breathing. In: Dahan A, Ward D, Teppema L, editors. Ventilatory effects of medications used for moderate and deep sedation. London: Taylor and Francis; 2005. p. 513-70.

6. Boyett MR, Honjo H, Kodama I. The sinoatrial node, a heterogeneous pacemaker structure. Cardiovasc Res. 2000;47: $658-87$.
7. Rohr S. Role of gap junctions in the propagation of the cardiac action potential. Cardiovasc Res. 2004;62:309-22.

8. Bers DM. Cardiac excitation-contraction coupling. Nature. 2002;415:198-205.

9. Hanley PJ, ter Keurs HEDJ, Cannell MB. Excitation-contraction coupling in the heart and the negative inotropic action of volatile anesthetics. Anesthesiology. 2004;101:999-1014.

10. Ramirez J-M. The human pre-Botzinger complex identified. Brain. 2011;134:8-10.

11. Alheid GF, McCrimmon DR. The chemical neuroanatomy of breathing. Respir Physiol Neurobiol. 2008;164:3-11.

12. Onimaru H, Homma I, Feldman JL. Point:Counterpoint: The parafacial respiratory group ( $\mathrm{pFRG}$ )/pre-Botzinger complex (preBotC) is the primary site of respiratory rhythm generation in the mammal. J Appl Physiol. 2006;100:2094-8.

13. Feldman JL, Del Negro CA. Looking for inspiration: new perspectives on respiratory rhythm. Nature Rev Neurosci. 2006;7:232-42.

14. Rekling JC, Feldman JL. PreBotzinger complex and pacemaker neurons: hypothesized site and kernel for respiratory rhythm generation. Ann Rev Physiol. 1998;60:385-405.

15. Onimaru H, Arata A, Homma I. Localization of respiratory rhythm-generating neurons in the medulla of brainstem-spinal cord preparations from newborn rats. Neurosci Lett. 1987;78: $151-5$.

16. Onimaru H, Homma I. Respiratory rhythm generator neurons in medulla of brainstem-spinal cord preparation from newborn rat. Brain Res. 1987;403:380-4.

17. Onimaru H, Arata A, Homma I. Primary respiratory rhythm generator in the medulla of brainstem-spinal cord preparation from newborn rat. Brain Res. 1988;445:314-24.

18. Smith JC, Ellenberger HH, Ballanyi K, et al. Pre-botzinger complex: a brainstem region that may generate respiratory rhythm in mammals. Science. 1991;254:726-9.

19. Guyenet PG, Mulkey DK. Retrotrapezoid nucleus and parafacial respiratory group. Respir Physiol Neurobiol. 2010;173:244-55.

20. Blanchi B, Kelly LM, Viemari J-C, et al. MafB deficiency causes defective respiratory rhythmogenesis and fatal central apnea at birth. Nat Neurosci. 2003;6:1091-9.

21. Jacquin TD, Borday V, Schneider-Maunoury S, et al. Reorganization of pontine rhytymogenic neuronal networks in Krox-20 knockout mice. Neuron. 1996;17:747-58.

22. Doi A, Ramirez JM. Neuromodulation and the orchestration of the respiratory rhythm. Respir Physiol Neurobiol. 2008;164: 96-104.

23. Williams RH, Jensen LT, Verkhratsky A, Fugger L, Burdakov D. Control of hypothalamic orexin neurons by acid and $\mathrm{CO}_{2}$. PNAS. 2007;104:10685-90.

24. Hodges MR, Richerson GB. The role of medullary serotonin (5-HT) neurons in respiratory control: contributions to eupneic ventilation, $\mathrm{CO}_{2}$ chemoreception, and thermoregulation. J Appl Physiol. 2010;108:1425-32.

25. Putnam RW. $\mathrm{CO}_{2}$ chemoreception in cardiorespiratory control. J Appl Physiol. 2010;108:1796-802.

26. Lopez-Barneo J, Ortega-Saenz P, Pardal R, et al. Carotid body oxygen sensing. Eur Resp J. 2008;32:1386-98.

27. Montaldo-Caruana B, Gleeson K, Zwillich CW. The control of breathing in clinical practice. Chest. 2000;117:205-25.

28. Lopez-Barneo J, Pardal R, Ortega-Saenz P. Cellular mechanisms of oxygen sensing. Annu Rev Physiol. 2001;63:259-87.

29. Roy A, Rozanov C, Mokashi A, et al. Mice lacking gp91 phox subunit of NAD(P)H oxidase showed glomus cell $\left[\mathrm{Ca}^{2+}\right]$ and respiratory responses to hypoxia. Brain Res. 2000;872:188-93.

30. Archer SL, Reeve HL, Michelakis E, et al. $\mathrm{O}_{2}$ sensing is preserved in mice lacking the gp91 phox subunit of NADPH oxidase. Proc Natl Acad Sci USA. 1999;96:7944-9. 
31. Buckler KJ, Williams BA, Honore E. An oxygen-, acid-, and anesthetic sensitive TASK-like background potassium channel in rat arterial chemoreceptor cells. J Physiol. 2000;525:135-42.

32. Trapp S, Aller IM, Wisden W, et al. A role for TASK-1 (KCNK3) channels in the chemosensory control of breathing. J Neurosci. 2008;28:8844-50.

33. Ortega-Saenz P, Levitsky KL, Marcos-Almaraz MT, et al. Carotid body chemosensory responses in mice deficient of TASK channels. J Gen Physiol. 2010;135:379-92.

34. Ezure K. Synaptic connections between medullary respiratory neurons and considerations on the genesis of respiratory rhythm. Prog Neurobiol. 1990;35:429-50.

35. Iscoe S. Control of abdominal muscles. Prog Neurobiol. 1998;56:433-506.

36. Lazarenko RM, Fortuna MG, Shi Y, et al. Anesthetic activation of central respiratory chemoreceptor neurons involves inhibition of a THIK-1-like background $\mathrm{K}+$ current. $\mathrm{J}$ Neurosci. 2010;30:9324-34.

37. Matthew HWD, Maldonado R, Simonin F, et al. Loss of morphine-induced analgesia, reward effect and withdrawal symptoms in mice lacking the $\mu$-opioid-receptor gene. Nature. 1996;383:819-23.

38. Sora I, Tkahashi N, Funada M, et al. Opiate receptor knockout mice define mu receptor roles in endogenous nociceptive responses and morphine-induced analgesia. Proc Natl Acad Sci USA. 1997;94:1544-9.

39. Dahan A, Sarton E, Teppema L, et al. Anesthetic potency and influence of morphine and sevoflurane on respiration in $\mu$-opioid receptor knockout mice. Anesthesiology. 2001;94:824-32.

40. Pattison KTS. Opioids and the control of respiration. $\mathrm{Br} \mathrm{J}$ Anaesth. 2008;100:747-58.

41. Mellen NM, Janczewski WA, Bocchiaro CM, et al. Opioidinduced quantal slowing reveals dual networks for respiratory rhythm generation. Neuron. 2003;37:821-6.

42. Romberg R, Olofsen E, Sarton E, et al. Pharmacodynamic effect of morphine-6-glucuronide versus morphine on hypoxic and hypercapnic breathing in healthy volunteers. Anesthesiology. 2003;99:788-98.

43. Bianchi AL, Denavit-Saubie M, Champagnat J. Central control of breathing in mammals: neuronal circuitry, membrane properties and neurotransmitters. Physiol Rev. 1995;75:1-45.

44. Garner SJ, Eldridge FL, Wagner PG, et al. Buspirone, an anxiolytic drug that stimulates respiration. Am Rev Respir Dis. 1989;139:946-50.

45. Sahibzada N, Ferreira M, Wasserman AM, et al. Reversal of morphine-induced apnea in the anesthetized rat by drugs that activate 5-hydroxytryptamine(1A) receptors. J Pharmacol Exp Ther. 2000;292:704-13.

46. Wang X, Dergacheva O, Kamendi H, et al. 5-hydroxytryptamine $1 \mathrm{~A} / 7$ and $4 \alpha$ receptors differentially prevent opioid-induced inhibition of brainstem cardiorespiratory function. Hypertension. 2007;50:368-76.

47. Guenther U, Manzke T, Wrigge H, et al. The counteraction of opioid-induced ventilatory depression by the serotonin 1Aagonist 8-OH-DPAT does not antagonize antinociception in rats in situ and in vivo. Anesth Analg. 2009;108:1169-76.

48. Guenther U, Wrigge $\mathrm{H}$, Theuerkauf $\mathrm{N}$, et al. Repinotan, a selective $5-\mathrm{HT}_{1 \mathrm{~A}}-\mathrm{R}$ agonist, antagonizes morphine-induced ventilatory depression in anesthetized rats. Anesth Analg. 2010;111:901-7.

49. • Guenther U, Theuerkauf NU, Huse D, et al. Selective 5-HT $1 \mathrm{~A}^{-\mathrm{R}}$ agonist repinotan prevents remifentanil-induced ventilatory depression and prolongs antinociception. Anesthesiology. 2012;116: 56-64. In a rat model, repinotan blunted remifentanil-induced ventilatory depression while enhancing and prolonging the analgesic effect of the opioid.
50. Manzke T, Guenther U, Ponimaskin EG, et al. 5-HT4 (a) receptors avert opioid-induced breathing depression without loss of analgesia. Science. 2003;301:226-9.

51. Oertel BG, Schneider A, Rohrbacher M, et al. The partial 5-hydroxytryptamine1A receptor agonist buspirone does not antagonize morphine-induced respiratory depression in humans. Clin Pharmacol Ther. 2007;81:59-68.

52. Lotsch J, Skarke C, Schneider A, Hummel T, et al. The 5-hydroxytryptamine 4 receptor agonist mosapride does not antagonize morphine-induced respiratory depression. Clin Pharmacol Ther. 2005;78:278-87.

53. Greer JJ, Smith JC, Feldman JL. The role of excitatory amino acids in the generation and transmission of respiratory drive in the neonatal rat. J Physiol. 1991;437:727-49.

54. Arai AC, Kessler M. Pharmacology of ampakine modulators: from AMPA receptors to synapses and behavior. Curr Drug Targets. 2007;8:583-602.

55. Ren J, Poon BY, Tang Y, et al. Ampakines alleviate respiratory depression in rats. Am J Respir Crit Care Med. 2006;174: 1384-91.

56. Ren J, Ding X, Funk GD, et al. Ampakine CX717 protects against fentanyl-induced respiratory depression and lethal apnea in rats. Anesthesiology. 2009;110:1364-70.

57. • Oertel BG, Felden L, Tran PV, et al. Selective antagonism of opioid-induced ventilatory depression by an ampakine molecule in humans without loss of opioid analgesia. Clin Pharmacol Ther. 2010;87:204-11. In healthy volunteers, coadministration of the ampakine CX717 partially antagonizes alfentanil-induced ventilatory depression without affecting analgesia.

58. •• Ren J, Lenal F, Yang M, Ding X, Greer JJ. Coadministration of the ampakine CX717 with propofol reduces respiratory depression and fatal apneas. Anesthesiology. 2013;118:1437-45. In an intact rat preparation, the ampakine CX717 reduces but does not eliminate propofol-induced respiratory depression.

59. Taylor MB, Grounds RM, Mulrooney PD, et al. Ventilatory effects of propofol during induction of anaesthesia. Anaesthesia. 1986;41:816-20.

60. Grounds RM, Maxwell DL, Taylor MB, et al. Acute ventilatory changes during IV induction of anaesthesia with thiopentone or propofol in man. Br J Anaesth. 1987;59:1098-102.

61. Mackenzie N, Grant IS. Comparison of the new emulstion formulation of propofol with methohexitone and thiopentone for induction of anaesthesia in day cases. Br J Anaesth. 1985;57:725-31.

62. Mackenzie N, Grant IS. Comparison of propofol with methohexitone in the provision of anaesthesia for surgery under regional blockade. Br J Anaesth. 1985;57:1167-72.

63. Spens HJ, Drummond GB. Ventilatory effects of eltanolone during induction of anaesthesia: comparison with propofol and thiopentone. Br J Anaesth. 1996;77:194-9.

64. Goodman NW, Black AMS, Carter JA. Some ventilatory effects of propofol as sole anaesthetic agent. Br J Anaesth. 1987;59: $1497-503$

65. Jessop E, Grounds RM, Morgan M, et al. Comparison of infusions of propofol and methohexitone to provide light general anaesthesia during surgery with regional blockade. Br J Anaesth. 1985;57:1173-7.

66. Doze VA, Westphal LM, White PF. Comparison of propofol with methohexital for outpatient anesthesia. Anesth Analg. 1986;65:1189-95.

67. Blouin RT, Conard PF, Gross JB. Time course of ventilatory depression following induction doses of propofol and thiopental. Anesthesiology. 1991;75:940-4.

68. Nieuwenhuijs D, Sarton E, Teppema L, et al. Respiratory sites of action of propofol: absence of depression of peripheral chemoreflex loop by low-dose propofol. Anesthesiology. 2001;95: 889-95. 
69. Zhou W, Fontenot J, Liu S, et al. Modulation of cardiac calcium channels by propofol. Anesthesiology. 1997;86:670-5.

70. DeRuijter W, Stienen GJM, van Klarenbosch J, et al. Negative and positive inotropic effects of propofol via L-type calcium channels and the sodium-calcium exchanger in rat cardiac trabeculae. Anesthesiology. 2002;97:1146-55.

71. Fassl J, High KM, Stephenson ER, et al. The intravenous anesthetic propofol inhibits L-type calcium channels by enhancing voltage-dependent inactivation. J Clin Pharmacol. 2011;51:719-30.

72. Lawton BK, Brown NJ, Reilly CS, et al. Role of L-type calcium channels in altered microvascular responses to propofol in hypertension. Br J Anaesth. 2012;108:929-35.

73. Filosa JA, Putnam RW. Multiple targets of chemosensitive signaling in locus coeruleus neurons: role of $\mathrm{K}+$ and Ca2 + channels. Am J Physiol Cell Physiol. 2003;284:C145-55.

74. Munson ES, Larson CP, Babad AA, et al. The effects of halothane, fluroxene and cyclopropane on ventilation: a comparative study in man. Anesthesiology. 1966;27:716-28.

75. Fourcade HE, Stevens WC, Larson P, et al. The ventilatory effects of forane, a new inhaled anesthetic. Anesthesiology. 1971;35:26-31.

76. Knill RL, Kieraszewicz HT, Dodgson BG, et al. Chemical regulation of ventilation during isoflurane sedation and anaesthesia in humans. Can Anaesth Soc J. 1983;30:607-14.

77. Doi M, Ikeda K. Respiratory effects of sevoflurane. Anesth Analg. 1987;66(241-4):4.

78. Lockhart SH, Rampil IJ, Yasuda N, et al. Depression of ventilation by desflurane in humans. Anesthesiology. 1991;74:484-8.

79. Temp JA, Henson LC, Ward DS. Does a subanesthetic concentration of isoflurane blunt the ventilatory response to hypoxia? Anesthesiology. 1992;77:1116-24.

80. Sollevi A, Lindahl SG. Hypoxic and hypercapnic ventilatory responses during isoflurane sedation and anaesthesia in women. Acta Anaesth Scand. 1995;39:17-22.

81. Pandit JJ, Manning-Fox J, Dorrington KL, et al. Effects of subanesthetic sevoflurane on ventilation. 1: response to acute and sustained hypercapnia in humans. Br J Anaesth. 1999;83:204-9.

82. Van den Elsen M, Dahan A, DeGoede J, et al. Influence of subanesthetic isoflurane on ventilatory control in humans. Anesthesiology. 1995;83:478-90.

83. Van den Elsen M, Sarton E, Teppema L, et al. Influence of 0.1 minimum alveolar concentration of sevoflurane, desflurane and isoflurane on dynamic ventilatory response to hypercapnia in humans. Br J Anaesth. 1998;80:174-8.

84. Gal TJ, DiFazio CA, Moscicki J. Analgesic and respiratory depressant activity of nalbuphine: a comparison with morphine. Anesthesiology. 1982;57:367-74.

85. Blouin RT, Seifert HA, Babenco HD, et al. Propofol depresses the hypoxic ventilatory response during conscious sedation and isohypercapnia. Anesthesiology. 1993;79:1177-82.

86. Nagyova B, Dorrington KL, Gill EW, et al. Comparison of the effects of sub-hypnotic concentrations of propofol and halothane on the acute ventilatory response to hypoxia. $\mathrm{Br} \mathrm{J}$ Anaesth. 1995;75:713-8.

87. Nieuwenhuijs D, Sarton E, Teppema L, et al. Propofol for monitored anesthesia care: implications on hypoxic control of cardiorespiratory responses. Anesthesiology. 2000;92:46-54.

88. Radke-Klockgether AP, Schulze H, Neumann P, et al. Activation of the $\mathrm{K}^{+} \mathrm{BK}(\mathrm{Ca})$ is involved in the relaxing effect of propofol on coronary arteries. Eur J Anaesthesiol. 2004;21:226-30.

89. Muravchick S, Levy RJ. Clinical implications of mitochondrial dysfunction. Anesthesiology. 2006;105:819-37.
90. Joensnen H, Sadler CL, Ponte J, et al. Isoflurane does not depress the hypoxic response of rabbit carotid body chemoreceptors. Anesth Analg. 2009;91:480-5.

91. Robotham JL. Do low-dose inhalational anesthetic agents alter ventilatory control? Anesthesiology. 1994;80:723-6.

92. Sjogren D, Sollevi A, Ebberyd A, et al. Poikilocapnic hypoxic ventilatory response in humans during 0.85 MAC isoflurane anesthesia. Acta Anaesthiol Scand. 1994;38:149-55.

93. Sjogren D, Sollevi A, Ebberyd A, et al. Isoflurane anaesthesia (0.6 MAC) and hypoxic ventilatory responses in humans. Acta Anaesthiol Scand. 1995;39:17-22.

94. Dahan A, Sarton E, van den Elsen M, et al. Ventilatory response to hypoxia in humans: influence of subanesthetic desflurane. Anesthesiology. 1996;85:60-8.

95. Patel AJ, Honore E. Anesthetic-sensitive $2 \mathrm{P}$ domain $\mathrm{K}^{+}$channels. Anesthesiology. 2001;95:1013-21.

96. Teppema LJ, Romberg RR, Dahan A. Antioxidants reverse reduction of the human hypoxic ventilatory response by subanesthetic isoflurane. Anesthesiology. 2005;102:747-53.

97. Zhang Y, Zhipeng X, Wang H, et al. Anesthetics isoflurane and desflurane differently affect mitochondrial function, learning and memory. Ann Neurol. 2012;71:689-98.

98. Lemoine S, Buleon C, Rouet R, et al. Bradykinin and adenosine receptors mediate desflurane induced postconditioning in human myocardium: role of reactive oxygen species. BMC Anesthesiology. 2010;10:12.

99. Perrelli M-G, Pagliaro P, Penna C. Ischemia/reperfusion injury and cardioprotective mechanisms: role of mitochondria and reactive oxygen species. World J Cardiol. 2011;3:186-200.

100. Stuth EAE, Tonkovic-Capin M, Kampine JP, et al. Dosedependent effects of isoflurane on the $\mathrm{CO}_{2}$ responsiveness of expiratory medullary neurons and the phrenic nerve activities in dogs. Anesthesiology. 1992;76:763-74.

101. Dogas Z, Stuth EAE, Hopp FA, et al. NMDA receptor-mediated transmission of carotid body chemoreceptor input to expiratory bulbospinal neurons in dogs. J Physiol. 1995;487:639-51.

102. Krolo M, Stuth EA, Tonkovic-Capin MN, et al. Relative magnitude of tonic and phasic synaptic excitation of medullary inspiratory neurons in dogs. Am J Physiol Regul Integrative Comp Physiol. 2000;279:R639-49.

103. Dogas Z, Krolo M, Stuth EA, et al. Differential effects of $\mathrm{GABA}_{\mathrm{A}}$ receptor antagonists in the control of respiratory neuronal discharge patterns. J Neurophysiol. 1998;80:2368-77.

104. Krolo M, Stuth EA, Tonkovic-Capin M, et al. Differential roles of ionotropic glutamate receptors in canine medullary inspiratory neurons of the ventral respiratory group. J Neurophysiol. 1999;82:60-8.

105. Stuth EAE, Krolo M, Tonkovic-Capin M, et al. Effects of halothane on synaptic neurotransmission to medullary expiratory neurons in the ventral respiratory group of dogs. Anesthesiology. 1999;91:804-14.

106. Stuth EAE, Krolo M, Stucke AG, Tonkovic-Capin M, et al. Effects of halothane on excitatory neurotransmission to medullary expiratory neurons in a decerebrate dog model. Anesthesiology. 2000;93:1474-81.

107. Stucke AG, Stuth EAE, Tonkovic-Capin V, et al. Effects of sevoflurane on excitatory neurotransmission to medullary expiratory neurons and on phrenic nerve activity in a decerebrate dog model. Anesthesiology. 2003;95:485-91.

108. Stucke AG, Stuth EAE, Tonkovic-Capin V, et al. Effects of halothane and sevoflurane on inhibitory neurotransmission to medullary expiratory neurons in a decerebrate dog model. Anesthesiology. 2002;96:955-62. 